\title{
Marketing life after advertising bans
}

While advertising bans severely restrict the capacity of the tobacco industry to promote its products, it is intriguing to consider how the millions of dollars the industry was previously able to roll out for print, electronic, billboard, and point of sale advertising campaigns is now being spent.

In Australia, all print, radio, and television advertisements are banned. Point of sale advertising is banned or being phased out in most jurisdictions, and only a handful of major international sporting events are able to be sponsored by the tobacco industry prior to a 2006 phase out. ${ }^{1}$ Yet the industry can still manage to spend tens of millions of dollars marketing its products. What do they spend this on? Insights were provided recently when advertising agency Belgiovane Williams Mackay (BWM) picked up the $\$$ A10 million account for the newest entrant into the Australian market, Imperial Tobacco, ${ }^{2}$ which controls just $16.5 \%$ of the market. ${ }^{3}$ BWM's advertising brief for Imperial was for "below the line" marketing activity, including point of sale material, packaging, events management, and relationship marketing.

Event promotion is a key strategy for tobacco companies to promote their products through displays, typically at glamorous party settings or popular events, often at adult venues, but always where teenagers or young adults are present in large numbers.

The brazen example described below involved an aggressive marketing strategy with an advertising agency that used the internet, leverage from non-tobacco brands, gifts with purchases of tobacco, and event based marketing (the sponsorship of young fashion designers' awards) as core strategies.

\section{Wavesnet}

In March 1996, Philip Morris became the owner of a trademark called Waves. ${ }^{4}$ It was used to distribute a magazine entitled Waves that offered a catalogue of trendy gift ideas and fashion shows aimed at a young female market. The catalogue contained some references to smoking and some subtle imagery evoking a connection with the PM menthol Alpine brand, such as images from the Alpine sponsored women's golf event and Alpine scenery reminiscent of the Alpine pack. Alpine is almost exclusively smoked by women.

The Waves trademark steadily built up a consumer database via the catalogue and value added gifts offers with tobacco purchase. These included a cosmetic pouch, cosmetic mirror, lip liner, diaries, and stylistic salt and pepper shakers with a free extra pack. The Waves strategy became a Trojan horse from which Philip Morris could unleash the next phase in its new strategy to extend the brand's appeal to younger women.

The strategy was launched in October 2000, when Wavesnet was registered as a company and a funky Wavesnet website established (www.wavesnet.net). The website, dealing with fashion, bars, and "hip" events and products, was established by Mojo, an advertising agency managing the PM Alpine account. ${ }^{5}$ A background search on the company revealed that the three directors and company secretary of Wavesnet were also directors of Mojo or of Publicis Communications, which controls Mojo. ${ }^{6}$ A Philip Morris spokesperson confirmed to the Herald Sun newspaper that Philip Morris licensed the use of the Wavesnet trademark to Publicis.

The website offers free passes and drinks to people who subscribe online. Subscribers enter personal details including name, address, telephone numbers, and email address into the compulsory fields in the online registration form. For their efforts, and even if under the age of 18 , they are immediately sent an email message stating in teen chatroom vernacular:

"you're in_wavesnet_your member no. is_u and friend now have_free entry_2 your state's fashion's future designer awards_ on the night_u get_ vip status_ free drinks_a bag_ full of free stuff_u get $2_{-}$rub shoulders with australia's top designers_all $\mathrm{u}$ have 2 do is rock up _ and your name will b@ the door_check out_your state's details@_wavesnet.net_cu there_"

The event in question was a glamorous fashion event "Who will you be wearing next?" promoting the work of young fashion designers.

Computer terminals at the Wavesnet events allowed attendees to sign up on site. Insiders have suggested that as many as 40000 people may be registered on the Wavesnet database. Wavesnet's general manager confirmed that there were plans to hold dance parties as well as fashion awards nights and that building up a database of members' likes and dislikes was one of the reasons for the existence of the Wavesnet website.

A key element of the strategy is affinity marketing-leveraging the power of iconic "todie-for" youth brands such as compact discs, confectionery, lingerie, and clothing with the target market. By using the Wavesnet brand and name, Philip Morris was able to keep the owners of these brands in the dark about the Philip Morris connection. When they learned of the links, all known sponsors expressed their outrage at the deception and withdrew their support. ${ }^{8}$ The website is also linked from other sites that appeal to young women, including www.femail.com.au, that had no idea that they were in fact dealing with a company backed by Philip Morris. ${ }^{9}$ 


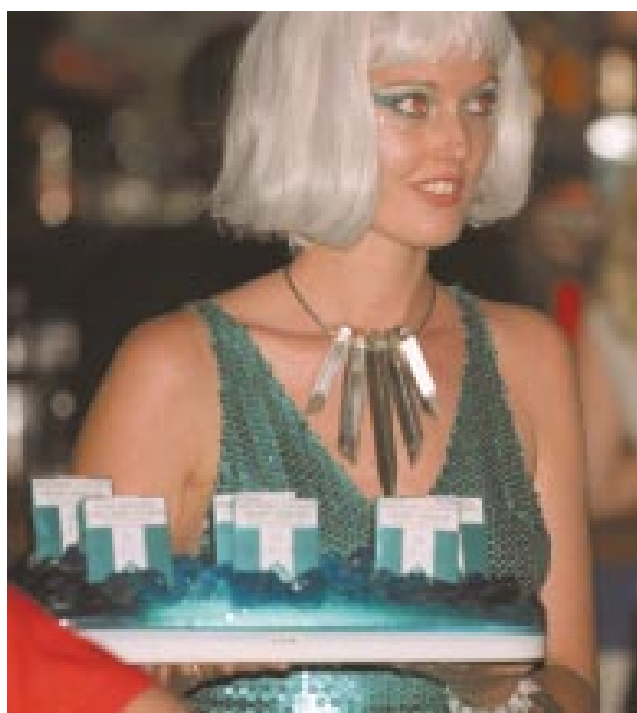

Figure 1 Making Waves. New events based marketing strategies promote a glamorous and youthful image. Photograph by Dean Martin, Adelaide Advertiser.

Neither the website nor the plethora of printed advertising materials reveals that Philip Morris pulls the strings of Wavesnet. In fact, where Philip Morris was mentioned, it was as a supporter along with several other corporate entities. There was nothing to suggest Philip Morris controls the operation. Very few, if any, attendees would be aware of the control that Philip Morris has over Wavesnet.

It is not just advertising bans the industry must counteract, but also poor public perceptions among Philip Morris' target audience. Would young people queue up to a tobacco company promotional event? Would they be willing to provide personal and identifying information to a tobacco company?

At the state final of the "Who will you be wearing next?" event in Melbourne, all attendees were given free gift packs including products from these companies which included lingerie, jewellery, herbal tea, mouse pads, magazines, CDs, and confectionery. There was an Alpine booth with young women dressed in Alpine green outfits selling the brand at about $\$ 1.50$ (or about $18 \%$ ) below the recommended retail price (fig 1 ). The venue featured extensive decorations in cigarette packet colours, while various high profile fashion identities and models were also in attendance. An unattended Alpine cigarette display was prominent throughout the night from which several patrons were observed taking packets, although staff assured attendees that they were not free samples, but only available for sale.

An organiser for other major events has revealed that, in return for handing over sponsorship dollars for an event on 15 December 2000, Philip Morris wanted "its corporate colours to be evident at the rave, and for cigarette sellers in fetching outfits to roam the dance floors looking for customers." ${ }^{10}$
Events promoters, particularly for dance parties, are receiving big support from the tobacco industry. As investigative journalists in Melbourne have revealed: "One promoter who has enjoyed British American Tobacco sponsorship for several events, says cigarette company involvement in raves keeps the punter's tickets low and the dance party scene flourishing." " And therefore achieves greater exposure of tobacco products to potential customers.

\section{The future}

It now appears that events marketing will remain a key element of the tobacco industry's future strategies in Australia. The gay community, young people, and rave and dance party patrons remain key targets. Quit Victoria is aware of more examples of "shelf" companies that have been established which have begun the process of marketing tobacco products at events.

Similar occurrences are now being reported in Europe, where BAT has been implicated in an internet marketing strategy that entices people to events promoted where the industry is able to expose them to their tobacco products. ${ }^{11}$

Vigilance in monitoring these activities that are marketed more directly to target markets is critical. Governments will now need to look at reforms that stem these practices, including bans on mobile retailing, and broader definitions of "tobacco advertisement" than have been addressed in current legislation. Restrictions should be broadened to include colours and imagery that evoke connections with tobacco brands, and electronic and audio messages, and to restrict further the display of tobacco products - ultimately banning tobacco packs from public display.

TODD HARPER

Quit Victoria,

100 Drummond Street,

Carlton 3053,

Victoria, Australia

todd.harper@accv.org.au

1 Wooldridge M. Australian Health Minister. Media release, 10 October, 2000. http://www.health.gov.au/mediarel $\mathrm{yr} 2000 / \mathrm{mw} / \mathrm{mw} 20100 . \mathrm{htm}$, accessed 23 January 2001

2 B\&T Weekly, 9 June 2000, p 2.

3 Philip Morris Australia Financial Report, 31 December 1999. Australian Securities and Investments Commission, http://www.asc.gov.au, accessed 24 November 2000

4 Intellectual Property Australia, http://pericles.ipaustralia. gov.au/atmoss/falcon. application_start, accessed 4 December 2000 .

5 AC Nielson Top 100. Retail World 16-17 November 2000, p 13.

6 Murrill M. Business briefs. Business Review Weekly 2000; 22(46). http://www.brw.com.au/newsadmin/stories/brw/ 20001124/8058.htm, accessed 23 January 2001.

7 Moor, K. Teenage fun bankrolled by tobacco giant. Herald Sun 11 December 2000, p 4. http://news.com.au/common/ story page $/ 0,4057,1506226 \% 255 \mathrm{E} 421,00 . \mathrm{html}$, accessed 23 January 2001 .

8 Moor K. Herald Sun, 11 December 2000, p 4.

9 Moor K. Herald Sun, 11 December 2000, p 15.

10 Te Koha N. Herald Sun, 14 December 2000, p 18

11 Rogers D.The Guardian 24 January 2001 